Neurosurg Focus 9 (3):E1, 2000

\title{
Distraction osteogenesis for craniosynostosis
}

\author{
Tanetaka Akizuki, M.D., Yuzo Komuro, M.D., And Kitaro Ohmori, M.D. \\ Department of Plastic Surgery, Tokyo Metropolitan Police Hospital, Tokyo, Japan
}

\begin{abstract}
Object. The authors describe the use of distraction devices and surgical techniques of distraction osteogenesis for the treatment of patients with craniosynostosis.

Methods. Since 1994, the authors have performed distraction procedures in 23 patients with craniosynostosis in whom osteogenesis was achieved. Thirteen of the 23 patients underwent a complete Le Fort III midface osteotomy and distraction. In 10 patients the distraction osteogenesis involved the cranial bone; six underwent combined forehead and midface distraction (Le Fort IV distraction) in which multiple internal devices were used after performing a Le Fort IV osteotomy.

An external distraction procedure was used to treat the first two cases. Since 1996, the authors have used internal devices developed in their unit.

Distraction was initiated 1 week after the osteotomy at the rate of $0.5 \mathrm{~mm}$ per day for the cranium and $1.0 \mathrm{~mm}$ per day for the midface. The consolidation phase after distraction was initiated was 2 to 3 months.

No major complications such as intracranial infection or neurological deficits were observed during the course of distraction osteogenesis. The osteogenesis generated at the distraction site was considerably satisfactory; and recurrence of the deformity in the follow-up period was minimal.

Conclusions. Distraction osteogenesis for craniofacial deformity has numerous advantages: 1) bone grafting is unnecessary; 2) the procedure is less invasive, has short operating time, and less blood loss occurs than in conventional craniofacial procedures; 3 ) no intracranial dead space is created; 4) there is a good amount of blood flow to the bone segment; and 5) soft-tissue expansion occurs. The authors believe that distraction osteogenesis is a versatile and stable option for the treatment of patients with craniosynostosis.
\end{abstract}

KEY WORDS • craniosynostosis • osteogenesis • craniofacial surgery • distraction

After the great success of distraction osteogenesis for long bones in orthopedic surgery, ${ }^{9}$ craniofacial distraction osteogenesis has become one of the most widely used and influential methods in the field of craniomaxillofacial surgery. Since McCarthy and colleagues ${ }^{12}$ first reported clinical cases in which distraction of the mandible was undertaken, the application of craniofacial distraction osteogenesis has been rapidly extended from the mandible ${ }^{13}$ to the midface ${ }^{6,7,15,17}$ and, further, to cranial bones. ${ }^{8,10,16}$

Since 1994 we have achieved osteogenesis of the cranium and the midface for the treatment of patients with craniosynostosis by undertaking craniofacial distraction. After the external distraction devices were used in the first 2 years (two cases), ${ }^{1}$ we developed internal distraction devices for the cranium and the midface in $1996 .{ }^{3}$ Since then, application of midface and cranium distraction for craniosynostosis in which we have used internal distraction devices has been undertaken for more than 20 cases.

Based on our results, we believe that distraction osteogenesis for craniosynostosis can be achieved in a safe and easy manner and that stable and satisfactory results can be obtained. ${ }^{1-4}$

\footnotetext{
Abbreviations used in this paper: ANS = anterior nasal spine; $\mathrm{CT}=$ computerized tomography; $3 \mathrm{D}=$ three dimensional; $\mathrm{N}$-ANS = nasion ANS; S-N = sellar-nasion.
}

In this paper, the distraction devices and the surgical technique of distraction osteogenesis for craniosynostosis are introduced, and representative cases are discussed.

\section{CLINICAL MATERIAL AND METHODS}

\section{Patient Population}

From December 1994 to June 2000, craniofacial distraction osteogenesis for craniosynostosis was performed in 23 cases. Twenty-one patients underwent a distraction procedure in which the device was placed within the wound, and in our first two patients an external distraction device was applied outside the wound. The patients ranged in age from 1 to 43 years (average age 14 years). The following syndromes were diagnosed: Crouzon syndrome in 12 cases; Apert syndrome in four; Pfeiffer syndrome in three; unicoronal synostosis (plagiocephaly) in two; bicoronal synostosis (brachycephaly) in one; and sagittal synostosis (scaphocephaly) in one case.

\section{Distraction Devices}

We used two craniofacial distraction devices: an external distraction device positioned outside the wound and an internal distraction device embedded in the wound. The external distraction device was applied in our first two 


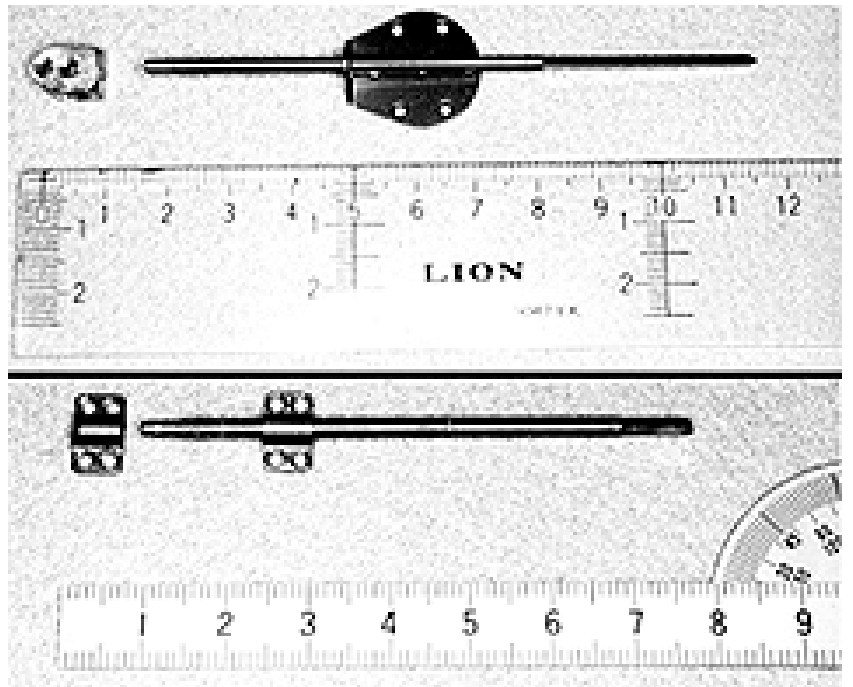

Fig. 1. Photographs showing the internal distraction devices for the midface (upper) and cranium (lower). Upper: The round and U-shaped plates are placed, respectively, on the temporal bone and the base of the zygomatic arch and secured using microscrews. Lower: Two small plates are placed on the cranial bone and secured using microscrews. The distal end of the axis is exposed from the scalp for activation. This device can be used universally for other craniofacial bones such as the mandible.

cases (in 1994 and 1995) after which the distraction device was applied internally in all patients.

There were some drawbacks associated with external distraction because the devices were not exclusively manufactured for craniofacial distraction and were too large, too conspicuous, and too heavy. Additionally, skin lacerations caused by movement of external fixation pins were likely to develop. To overcome these problems, we developed two internal distraction devices. Since 1996, we have used the devices to perform internal midface and cranium distraction procedures.

We devised two titanium three-part internal distraction devices, one for the midface and one for the cranium. The internal device used for midface distraction has three parts: a U-shaped hook, a round plate, and a distraction shaft (Fig. 1 upper). The U-shaped hook and the round plate are placed respectively, on the zygomatic bone and temporal bone and secured using microscrews. The threaded distraction shaft is $3 \mathrm{~mm}$ in diameter, and the length varies according to the application requirements in each case. Female threads are formed on a part of the round plate. When the distraction shaft is rotated by one turn, $0.5 \mathrm{~mm}$ of distraction is obtained. After the consolidation period, the shaft can be removed easily by turning it in the opposite direction. The other parts of the device may be removed or left in place, if no conspicuous extension is apparent.

The internal device for cranium distraction consists of two small plates and a shaft (Fig. 1 lower). The shaft is the same as that used in the midface device.

\section{Surgical Technique for Midface Distraction}

The midfacial region is extensively undermined below the periosteum via a coronal incision and bilateral subcil-

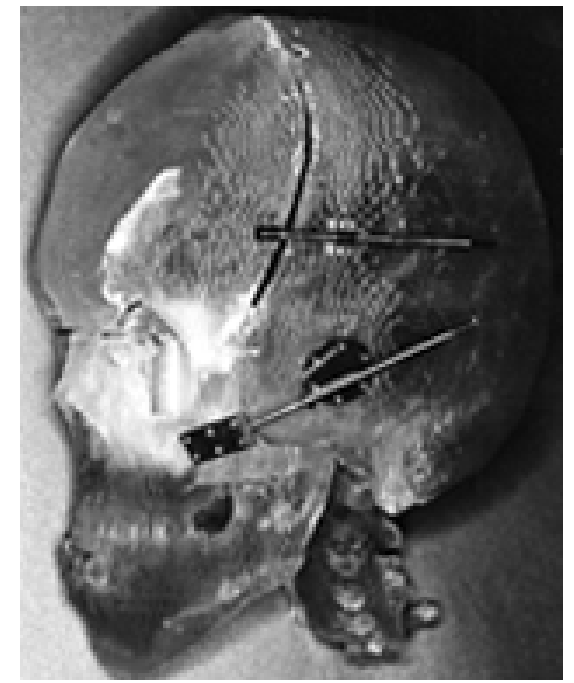

Fig. 2. Presurgical simulation of Le Fort IV distraction on a real-sized replica of a patient with Crouzon syndrome. The frontal bone is completely cut in one part from the upper half of the orbit. This part is never detached from the underlying dura. An endoscope inserted through a burr is used to guide the surgical cutting of the anterior cranial base. A conventional Le Fort III osteotomy is performed at the midface. The frontal bone is distracted in horizontal vector and the midface in anteroinferior vector according to the normal growth directions of the bones.

ia incisions of the lower eyelids. A Le Fort III osteotomy with complete mobilization is performed prior to the initiation of midface distraction. In undertaking the Le Fort III osteotomy the midface should be completely separated from the cranium. After being fully mobilized, the midface segment is restored to its original position. A pair of internal distraction devices are then symmetrically positioned bilaterally. The distraction vector of the midface is set in an anteroinferior direction according to the normal growth vector. The $\mathrm{U}$-shaped hook and the round plate are fixed, respectively, on the zygomatic bone and the temporal bone and secured using microscrews. The posterior end of the distraction shaft extends 2 to $3 \mathrm{~cm}$ outside of the scalp.

\section{Surgical Technique for Cranium Distraction}

A complete osteotomy of the cranial bone is performed using a craniotome; however, it is never detached from the underlying dura because adequate blood supply must be maintained. An internal distraction device is then placed on both sides of the osteotomy line and secured using microscrews. In the treatment of coronal synostosis, the frontal bone is surgically cut en bloc with the upper half of the orbit (the forehead complex) and distracted along the horizontal vector according to the direction of normal growth. The posterior end of the distraction shaft is extended by 2 to $3 \mathrm{~cm}$ outside the scalp.

In patients with has both forehead and midface hypoplasia, combination forehead and midface distraction (Le Fort IV distraction) is undertaken (Fig. 2). This procedure is achieved by undertaking a Le Fort III midface distraction combined with a forehead complex distraction procedure. The forehead and the midface are distracted in dif- 


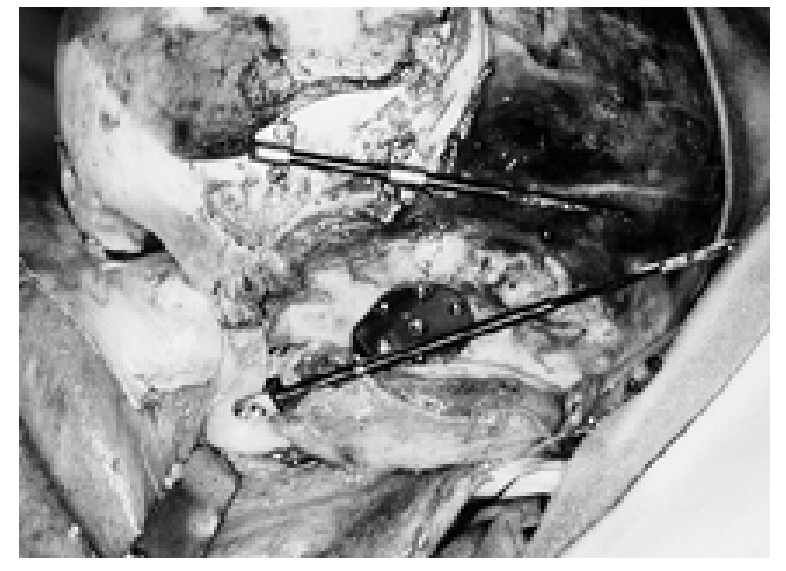

Fig. 3. Intraoperative photograph showing Le Fort IV distraction after placement of the internal devices.

ferent vectors according to the normal growth directions (Fig. 3).

\section{Distraction Phase}

Gradual distraction is initiated 1 week after the surgery, at a rate of $0.5 \mathrm{~mm}$ per day for the cranium and $1.0 \mathrm{~mm}$ per day for the midface. A lateral cephalogram and occlusal condition are assessed every week. After the distraction process is completed, callus maturation takes 2 to 3 months. During this period, the distraction shaft that extends outside the scalp is cut as short as possible.

There are no special restrictions in the patient's daily activity. Patients are allowed to bathe and wash their hair. Hair washing should be encouraged to prevent infection from the exposed part of the shaft.

At the end of the period during which callus maturation takes place, the distraction devices are removed after a general anesthesia has been induced. In the cases in which zygomatic bone plates and temporal bone plates are not extracranially conspicuous, only the distraction shaft may be withdrawn. The removal of the distraction shaft is accomplished by rotating the shaft in the reverse direction, and it can be conducted easily without the need for an anesthetic.

\section{RESULTS}

Thirteen of the 23 patients underwent a Le Fort III midface distraction procedure. In the remaining 10 cases the distraction involved the cranial bone (Table 1). Six patients underwent a Le Fort IV proceedure in which combined midface and forehead distraction was performed by placing multiple internal devices.

The average distraction lengths for the midface and the cranial bone were $17 \mathrm{~mm}$ and $10 \mathrm{~mm}$, respectively. Throughout the period during which distraction was being applied, there were no major complications such as intracranial infection or neurological deficits. As for minor complications, local infection, probably secondary to subcutaneous hematoma, was noted in two cases, but it subsided within 1 week, and distraction was continued thereafter without any additional problem. Dislocation of the
TABLE 1

Cases in which distraction osteogenesis was involved in the cranial bone

\begin{tabular}{|c|c|c|c|c|c|}
\hline $\begin{array}{l}\text { Case } \\
\text { No. }\end{array}$ & $\begin{array}{l}\text { Age } \\
\text { (yrs) }\end{array}$ & Disease & $\begin{array}{c}\text { Distraction } \\
\text { Type }\end{array}$ & $\begin{array}{c}\text { Distraction } \\
\text { Amount* }(\mathrm{mm})\end{array}$ & $\begin{array}{c}\text { Follow } \\
\text { Up } \\
(\mathrm{mos})\end{array}$ \\
\hline 1 & 7 & Crouzon & Le Fort IV & $\begin{array}{l}\text { cranium: } 9 \\
\text { midface: } 16\end{array}$ & 36 \\
\hline 2 & 3 & Crouzon & Le Fort IV & $\begin{array}{l}\text { cranium: } 10 \\
\text { midface: } 12\end{array}$ & 15 \\
\hline 3 & 28 & Crouzon & Le Fort IV & $\begin{array}{l}\text { cranium: } 16 \\
\text { midface: } 10\end{array}$ & 32 \\
\hline 4 & 42 & Crouzon & Le Fort IV & $\begin{array}{l}\text { cranium: } 6 \\
\text { midface: } 6\end{array}$ & 27 \\
\hline 5 & 6 & plagiocephaly & forehead & $\begin{array}{l}13 \text { (unilat) } \\
\text { cranium: } 10\end{array}$ & 18 \\
\hline 6 & 1 & Apert & Le Fort IV & $\begin{array}{l}\text { cranium: } 8 \\
\text { midface: } 10\end{array}$ & 16 \\
\hline 7 & 13 & Pfeiffer & Le Fort IV & midface: 20 & 13 \\
\hline 8 & 8 & brachycephaly & forehead & 10 (bilat) & 12 \\
\hline 9 & 6 & scaphocephaly & $\begin{array}{l}\text { forehead, } \\
\text { bitemporal }\end{array}$ & 7 (4 regions) & 12 \\
\hline 10 & 1 & plagiocephaly & forehead & 13 (unilat) & 10 \\
\hline
\end{tabular}

* Distraction amount was measured on the device.

distraction shaft occurred in one case, but this was easily restored under a fluoroscope, and the patient did not require an anesthetic.

\section{CASE ILLUSTRATIONS}

\section{Case 1}

This 7-year-old girl with Crouzon syndrome presented with brachycephaly and a hypoplastic midface (Fig. 4 left). A hypoplastic midface and a short anterior cranial base were demonstrated on 3D CT scanning (Fig. 4 center and right). She had undergone no previous craniofacial surgeries. We performed a Le Fort IV distraction, (combined midface and forehead distraction) after undertaking a Le Fort IV osteotomy. In the cranium, the frontal bone with the upper half of the orbit was not detached from the underlying dura. The midface and the forehead were simultaneously distracted in different directions by using two pairs of internal distraction devices. The frontal bone was distracted horizontally, and the midface was distracted in an anteroinferior direction.

The distraction process was initiated 1 week after the surgery, at a beginning rate of $1 \mathrm{~mm}$ per day for the midface and $0.5 \mathrm{~mm}$ per day for the cranium. After 22 days the frontal bone had been distracted by $9 \mathrm{~mm}$ and the midface by $16 \mathrm{~mm}$. Callus maturation was observed 2 months postdistraction. After this period, the internal distraction devices were removed after induction of general anesthesia (Fig. 5 upper left).

There were no treatment-related complications such as pain, bleeding, infection, or neurological deficits during the period in which distraction was applied.

On the postoperative 3D CT scan osteogenesis was demonstrated at the orbital rim and cranium (Fig. 5 upper right). The anterior cranial base was markedly enlarged (Fig. 5 lower left). The S-N distance changed from 58 

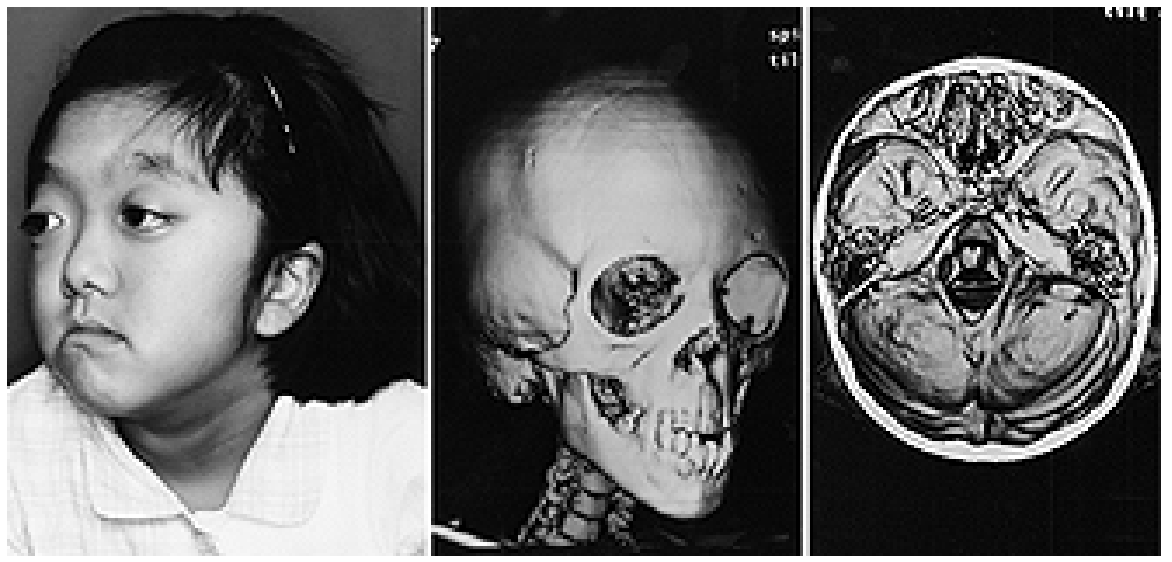

Fig. 4. Case 1. Left: Preoperative photograph. Note exophthalmos and hypoplastic midface. Center: Preoperative 3D CT scan. Right: Preoperative 3D CT scan of the cranial base. Note the obviously short anterior cranial base.

to $68 \mathrm{~mm}$, and the distance between nasion and ANS changed from 41 to $52 \mathrm{~mm}$ (Fig. 5 lower right).

\section{Case 2}

This 3-year-old girl with Crouzon syndrome underwent a Le Fort IV distraction (Fig. 6 upper left and center). The forehead complex was distracted horizontally by $8 \mathrm{~mm}$, and the midface was distracted anteroinferiorly by $12 \mathrm{~mm}$. The appearance was markedly improved after this procedure (Fig. 6 upper right). Postoperative 3D CT scanning revealed the forehead and midface were successfully distracted (Fig. 6 lower left). The S-N distance changed from 57 to $65 \mathrm{~mm}$, and the distance between the nasion and ANS changed from 37 to $42 \mathrm{~mm}$ (Fig. 6 lower right).

\section{Case 3}

This 28-year-old man with Crouzon syndrome had undergone multiple craniofacial osteotomies, including a conventional Le Fort IV osteotomy and advancement of the craniofacial skeleton in our unit. However, the patient suffered a relapse (Fig. 7 upper left and right). Because there were multiple bone defects on the craniofacial bone and an abscence of the soft-tissue elasticity due to scar formations, a Le Fort IV distraction was conducted. Two years postdistraction the patient had experienced almost no recurrence of the deformity (Fig. 7 lower).

\section{DISCUSSION}

\section{Distraction Device}

Of the two devices used in craniofacial distraction osteogenesis, one is externally applied to the wound and one is internally applied. In the external distraction device, ${ }^{15}$ halfpins that have a screw on one side are transcutaneously inserted into the bones proximal and distal to the osteotomy line, and these halfpins are attached to the external fixator to which the distraction mechanism is attached. The internal distraction device ${ }^{7}$ is fixed onto the bones and embedded subcutaneously except the one side of the shaft.

There are advantages and disadvantages to the two devices. The external distraction device is relatively large, and it is conspicuous in terms of its cosmetic appearance.
There are some limitations that interfere with daily life of the patients. The most remarkable disadvantage is that skin lacerations may be caused by the movement of halfpins. ${ }^{8}$ Moreover, the external device can hardly be used for cranial distraction because of the need to insert half-

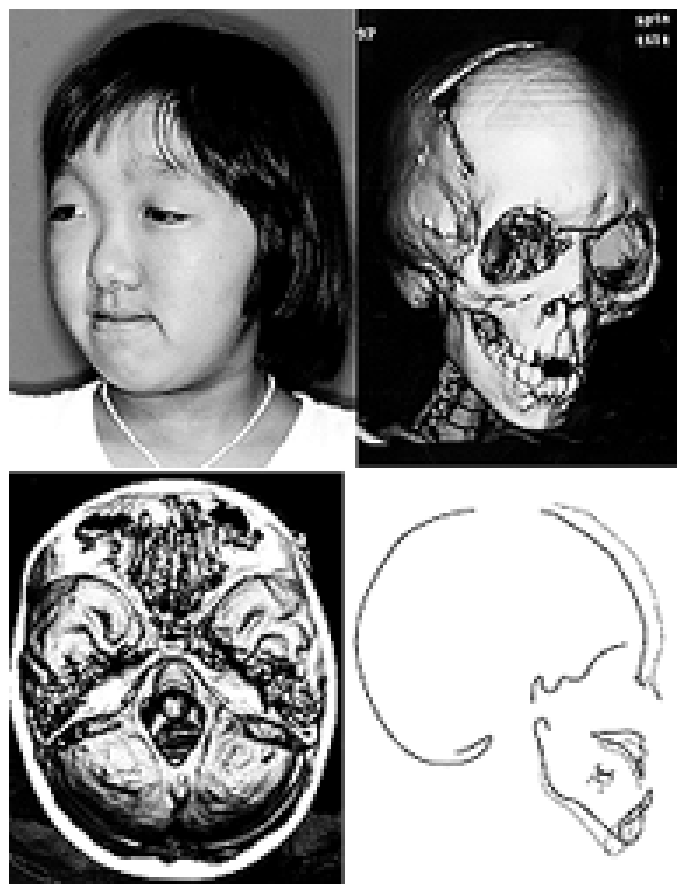

Fig. 5. Case 1. Postoperative studies. Upper Left: Photograph obtained 2 years postoperatively. The exophthalmos was well improved. The nose was lengthened. Upper Right: A 3D CT scan obtained 1 year postoperatively. Note the distracted forehead and midface. The orbits were markedly enlarged. Osteogenesis can be seen at the cranium, lateral orbital rim and the nasal root. Lower Left: A 3D CT scan obtained 1 year postoperatively. The anterior cranial base has been markedly enlarged. Lower Right: Illustration showing the lateral view of the changes that occurred after distraction. The solid line represents the preoperative state and the dotted line the condition 2 years postoperatively. The S-N distance changed from 58 to $68 \mathrm{~mm}$. The N-ANS distance changed from 41 to $52 \mathrm{~mm}$. 

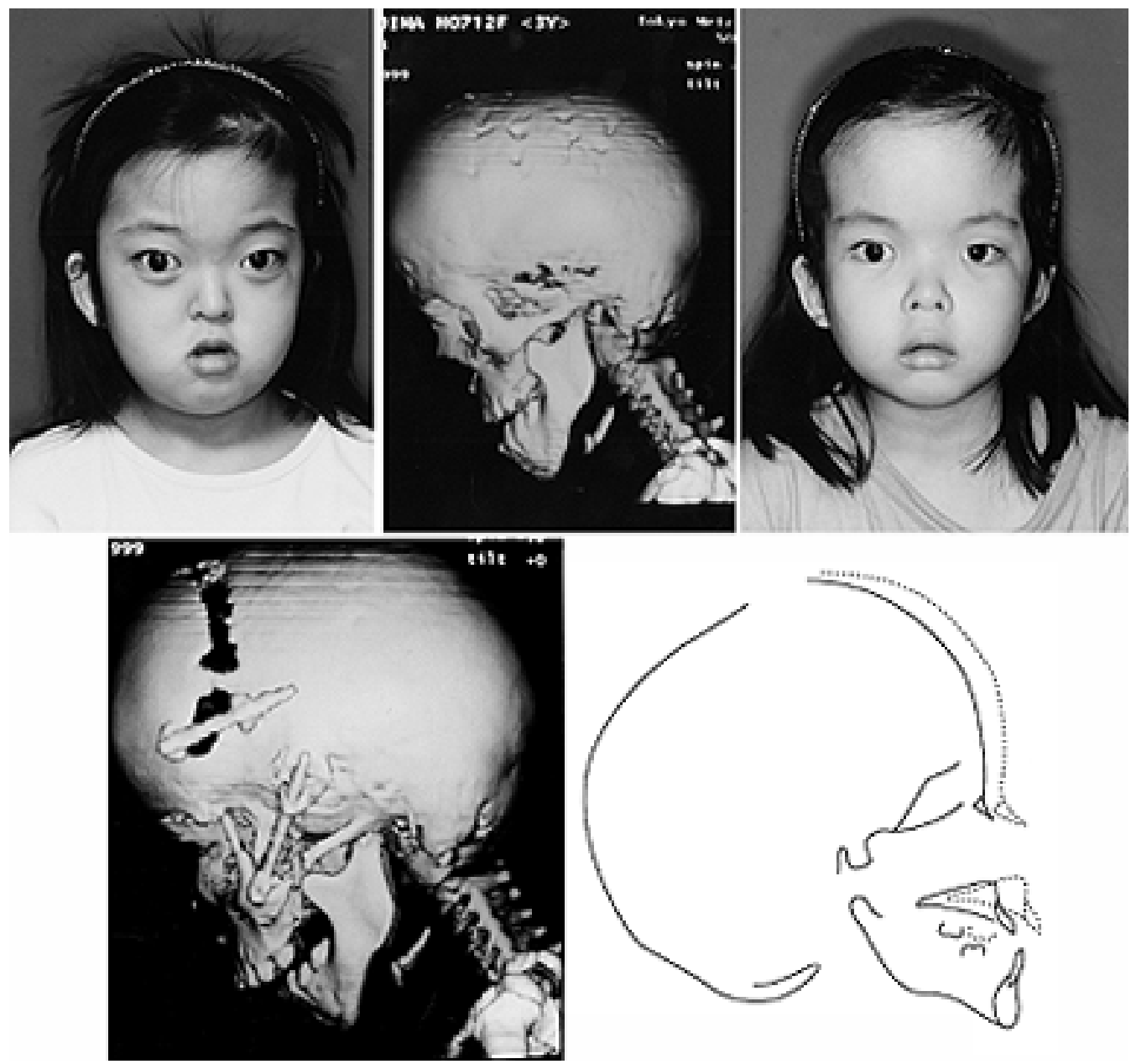

Fig. 6. Case 2. Upper Left: Preoperative photograph. Note exophthalmos and midface hypoplasia. Upper Center: Preoperative 3D CT scan demonstrating obvious midface hypoplasia. Upper Right: Photograph obtained 8 months postoperatively. The facial expression has markedly improved. Lower Left: A 3D CT scan obtained 4 months postoperatively (just before the device was removed). The forehead and the midface have been markedly distracted, but there is no evidence of osteogenesis yet. Note the improvements of the occlusion. Lower Right: Illustration showing the lateral view of changes that occurred. The solid line represents the preoperative state and the dotted line indicates the changes that occurred 8 months postoperatively. The S-N distance changed from 57 to $65 \mathrm{~mm}$, and the N-ANS distance changed from 37 to $42 \mathrm{~mm}$.

pins. Because of these disadvantages, the internal distraction device is now used in all cases at our facility.

Although the internal distraction device does not cause skin lacerations during the process of distraction, one of its disadvantages is that the surgical technique is somewhat complicated. Another disadvantage is that an additional surgical procedure is necessary to remove the devices after the completion of distraction osteogenesis.

\section{Advantage of Distraction Osteogenesis}

Compared with conventional craniofacial procedures, distraction osteogenesis has many advantage ${ }^{10,16}$ in that the operative time and blood loss are decreased, and the surgery is simple and less invasive. The most remarkable advantage is that bone grafting is not necessary. In the conventional method, craniofacial skeleton is advanced in a single stage, and bone graft material is implanted into the defect area created by the craniofacial advancement.
In cases in which the patients are infants or in patients who have repeatedly undergone craniofacial osteotomy, a sufficient quantity of bone graft material cannot be collected in many cases. If a sufficient quantity of bone graft cannot be implanted, then dead space is created at the defect site, and this often leads to postoperative infection or a high rate of bone resorption. Furthermore, this results in a recurrence of deformity. ${ }^{5}$ In the distraction osteogenesis, because dead space at the osteotomy site is rarely created, the possibility of postoperative infection or deformity recurrence is reduced compared with the conventional method.

In a patient with severe craniosynostosis, the cranial bone should be advanced substantially. In this case, an extradural longstanding dead space may be created just behind the advanced frontal bone. Moreover, the vascularity of the advanced frontal bone is absent or very poor in cases in which the conventional procedure is undertaken. ${ }^{5}$ 

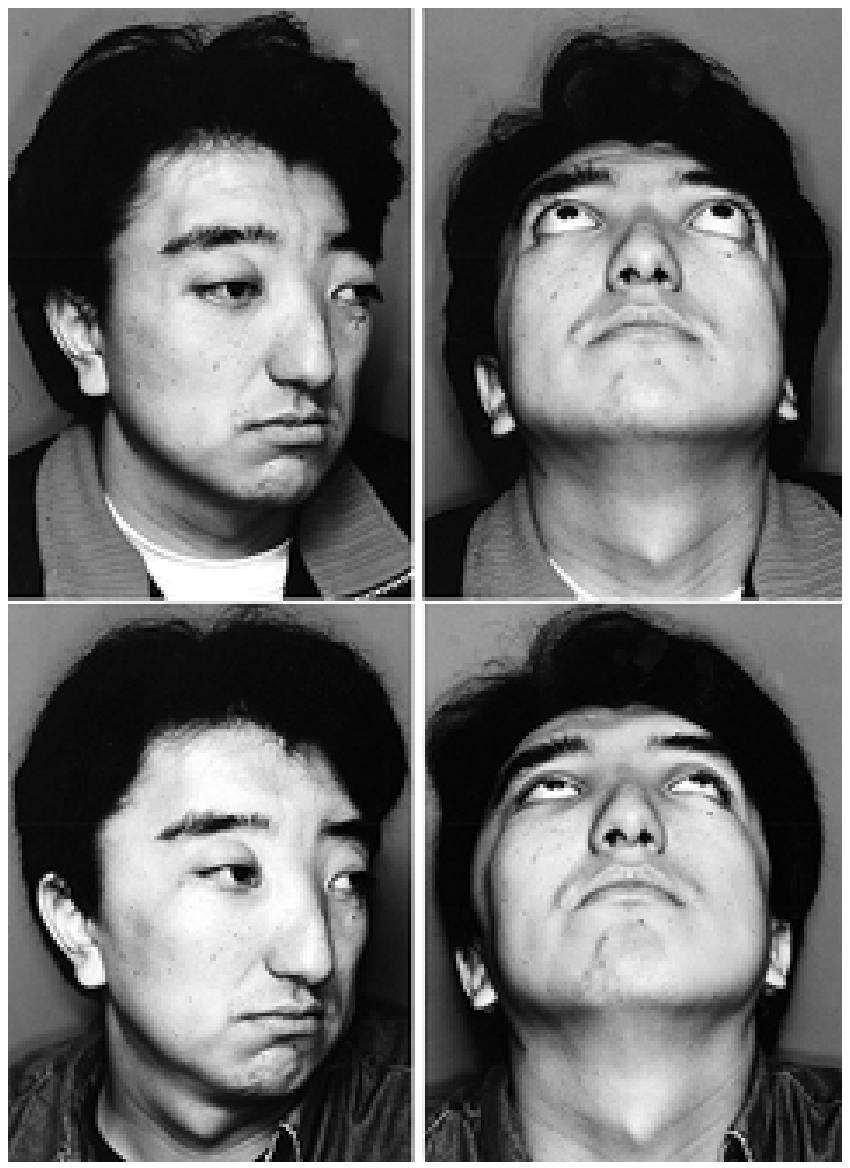

Fig. 7. Case 3. Upper Left: Preoperative photograph. Upper Right: Preoperative photograph, basal view. Note the exophthalmos. Lower Left: Photograph obtained 2 years postoperatively. Lower Right: Photograph (basal view) obtained 2 years postoperatively. The exophthalmos has improved.

In these circumstances, intracranial infection, which may cause a severe or lethal problem, tends to occur easily.

On the other hand, distraction osteogenesis has many advantages in that the surgically cut bone segment has good blood supply because it is never detached from the underlying dura. This means that almost no extradural dead space is produced. Because of these advantages, distraction osteogenesis is considerably safe in terms of intracranial infection.

In the cases in which a markedly hypoplastic skeleton is shown, the skeleton should be extensively advanced. The amount of craniofacial advancement is often limited because the extension of the soft tissues is limited. ${ }^{7}$ In the conventional surgical method, the distance of craniofacial advancement is limited to approximately $10 \mathrm{~mm}$ both in the cranium and the midface. On the other hand, in distraction osteogenesis, the soft tissues are also gradually distracted, and advancement of more than $20 \mathrm{~mm}$ may be achieved.

Regarding the fixation of the surgically cut bone segment when using the conventional method, the advanced skeleton must be firmly secured using multiple miniplates. In the cases of an infant, the bone at the fixation point may not be firm enough to bear the stress of the screws and plates. Furthermore, there is the additional problem of the plate becoming embedded in the bone because of bone growth after surgery. ${ }^{14}$ In such cases, distraction osteogenesis may be useful because vigorous potency of osteogenesis exists in the infant patient.

\section{Problems and Future Prospects}

In procedures involving distraction osteogenesis of the cranial bone, the procedure's influence on the brain, ventricles and intracranial pressure should be elucidated. ${ }^{8}$ The rate and maximum degree to which distraction is applied should be investigated to achieve a safe distraction of the cranium.

The essential issue in midface distraction osteogenesis is how to determine the proper vector of distraction. ${ }^{15} \mathrm{We}$ performed a simulation on a preoperative lateral cephalogram to determine the vector and the amount of distraction to be applied. Additional studies to elucidate these factors should be conducted.

The relapse of the distracted skeleton is also an essential issue to be solved in the future. It is our impression that the relapse of the distracted skeleton occurs less frequently in distraction osteogenesis, but a longer follow-up period is required to confirm this.

One of the future prospects of craniofacial distraction osteogenesis is to develop an entirely new osteotomy line not limited by bone grafting or bone fixation. Another future prospect is to undertake a much less invasive craniofacial distraction osteogenesis by using an endoscope ${ }^{11}$ and completely embedding the internal devices.

\section{CONCLUSIONS}

Since 1994, we have used distraction osteogenesis for the treatment of more than 20 patients with craniosynostosis. In our earliest treated cases, an external distraction procedure was conducted. Since 1996, after developing internal distraction devices, we have performed internal procedures in which the distraction devices are applied internally.

Hypoplastic skeletons such as frontal bone or midface were completely surgical split, the frontal bone distracted forward, and the midface distracted in the anteroinferior direction. In some cases, the midface and the forehead were simultaneously distracted by using multiple internal devices.

In our patients no major complications were demonstrated during the period in which distraction was being applied. The osteogenesis that developed at the distraction site was considered satisfactory, and relapse in the followup period was minimal.

Distraction osteogenesis for craniofacial skeletons has numerous advantages: 1) bone grafting is unnecessary; 2 ) the procedure is less invasive, has a shorter operating time, and there is less blood loss than in conventional craniofacial procedures; 3) no intracranial dead space is produced; 4) good blood flow to the bone segment is maintained; and 5) soft-tissue expansion occurs. We believe that distraction osteogenesis is in no way inferior to the conventional osteotomy and skeletal advancement.

There are many issues to be solved in this procedure such as type of distraction devices to use, the direction in 


\section{Distraction osteogenesis in craniosynostosis}

which the bone should be distracted, the speed at which distraction should be applied, and the length to which the cranium should be distracted, but it is expected that clinical application osteogenesis will be increasingly extended and propagated in the field of craniofacial surgery.

\section{References}

1. Akizuki T, Ohmori K: Mid-face distraction, in Marchac (ed): Craniofacial Surgery 6. Bologna: Monduzzi Editore, 1995, pp 283-285

2. Akizuki T, Ohmori K, Kobayashi S: Cephalometric analysis in clinical midface distraction, in Whitaker LA (ed): Craniofacial Surgery 7. Bologna: Monduzzi Editore, 1997, pp 67-70

3. Akizuki T, Ohmori K, Kobayashi S, et al: Midface distraction using internal fixation devices, in Diner PA, Vazquez MP (eds): International Congress on Cranial and Facial Bone Distraction Processes. Bologna: Monduzzi Editore, 1997, pp 281-287

4. Akizuki T, Ohmori K, Kurakata M, et al: Midface and cranium distraction using internal devices, in Diner PA, Vazquez MP (eds): 2nd International Congress on Cranial and Facial Bone Distraction Processes. Bologna: Monduzzi Editore, 1999, pp 239-246

5. Bartlett SP, Whitaker LA: Growth and survival of vascularized and nonvascularized membranous bone: an experimental study. Plast Reconstr Surg 84:783-788, 1989

6. Cedars MG, Linck DL II, Chin M, et al: Advancement of the midface using distraction techniques. Plast Reconstr Surg 103:429-441, 1999

7. Chin M, Toth BA: Le Fort III advancement with gradual distraction using internal devices. Plast Reconstr Surg 100: 819-832, 1997

8. do Amaral CMR, Di Domizio GD, Tiziani V, et al: Gradual bone distraction in craniosynostosis. Preliminary results in seven cases. Scand J Plast Reconstr Hand Surg 31:25-37, 1997
9. Ilizarov GA: Transosseous Osteosynthesis. Theoretical and Clinical Aspects of the Regeneration and Growth of Tissue. Berlin: Springer-Verlag, 1992, pp 453-543

10. Kobayashi S, Honda T, Saitoh A, et al: Unilateral coronal synostosis treated by internal forehead distraction. J Craniofac Surg 10:467-471, 1999

11. Levine JP, Rowe NM, Bradley JP, et al: The combination of endoscopy and distraction osteogenesis in the development of a canine midface advancement model. J Craniofac Surg 9: 423-432, 1998

12. McCarthy JG, Schreiber J, Karp N, et al: Lengthening the human mandible by gradual distraction. Plast Reconstr Surg 89: $1-10,1992$

13. Molina F, Ortiz-Monasterio F: Mandibular elongation and remodeling by distraction: a farewell to major osteotomies. Plast Reconstr Surg 96:825-842, 1995

14. Persing JA, Posnick J, Magge S, et al: Cranial plate and screw fixation in infancy: an assessment of risk. J Craniofac Surg 7: 267-270, 1996

15. Polley JW, Figueroa AA: Management of severe maxillary deficiency in childhood and adolescence through distraction osteogenesis with an external, adjustable, rigid distraction device. J Craniofac Surg 8:181-185, 1997

16. Sugawara Y, Hirabayashi S, Sakurai A, et al: Gradual cranial vault expansion for the treatment of craniofacial synostosis: a preliminary report. Ann Plast Surg 40:554-563, 1998

17. Toth BA, Kim JW, Chin M, et al: Distraction osteogenesis and its application to the midface and bony orbit in craniosynostosis syndromes. J Craniofac Surg 9:100-113, 1998

Manuscript received July 17, 2000.

Accepted in final form August 16, 2000.

Address reprint requests to: Tanetaka Akizuki, M.D., Plastic Surgery, Tokyo Metropolitan Police Hospital, 2-10-41, Fujimi, Chiyoda-ku, Tokyo 102-8161, Japan. email: soaring@st.rim.or.jp. 